\title{
A metodologia WebQuest no ensino de História: uma experiência com estudantes da educação básica
}

The WebQuest Methodology in History Teaching: An Experience with Students of Elementary and High School

Éder Dias do Nascimento*

Fábio André Hahn**

\section{RESUMO}

Integrar as tecnologias à prática docente tem sido um grande desafio para o sistema educacional brasileiro nestas primeiras décadas do século XXI, principalmente no que diz respeito ao uso da internet nas diferentes disciplinas. $\mathrm{O}$ presente artigo apresenta um estudo sobre as contribuições da metodologia de navegação orientada WebQuest para o ensino de História aplicada em uma escola pública. Seus resultados evidenciaram que, além da necessidade da constante reflexão sobre os elementos formais da metodologia WebQuest, é relevante pensar sobre ela considerando o protagonismo dos estudantes e a forma específica de como eles se apropriam das tecnologias.

Palavras-chave: ensino de História; metodologia WebQuest; uso da internet.

\section{ABSTRACT}

Integrating technologies into teaching has been a great challenge for the Brazilian educational system in these first decades of the 21st century, especially with regard to the use of Internet in different disciplines. This article presents a study on the contributions of the oriented navigation methodology WebQuest to the teaching of applied History in a public school. Its results showed that, in addition to the need for constant reflection on the formal elements of the WebQuest methodology, it is relevant to think about it considering the key role of students and the specific way they embrace and adopt technologies. Keywords: History teaching; WebQuest methodology; use of the Internet.

Em qual destes sites eu entro primeiro? Teremos que ler todos estes textos? São poucos os professores da educação básica que nunca se depararam com per-

\footnotetext{
* Secretaria de Estado da Educação do Paraná (SEED), Curitiba, PR, Brasil. ederptga@gmail.com

** Universidade Estadual do Paraná (UNESPAR), campus de Campo Mourão. Campo Mourão, PR, Brasil. fabioandreh@gmail.com
} 
guntas como estas feitas pelos estudantes quando eles realizam pesquisas na internet. Esta ferramenta comunicacional, além de alterar o ritmo de vida da nossa sociedade ao mobilizar enorme fluxo de informações acessíveis e instantâneas, tem requerido novas estratégias de construção do conhecimento no espaço escolar. Perante essa demanda específica, neste artigo apresentamos um estudo sobre o uso da metodologia de navegação orientada WebQuest para o ensino de História.

O criador desta metodologia, Bernie Dodge, ${ }^{1}$ define-a como uma lição em forma de "tarefas executáveis e interessantes" (1997). Ela foi desenvolvida em 1995, quando Dodge, coordenando um programa de capacitação de professores, tinha que apresentar um software educacional. Isso o levou a criar uma situação em que os participantes deveriam se imaginar como um tipo de consultor responsável por avaliar o programa de computador em questão e depois recomendá-lo ao diretor da escola. O resultado da prática possibilitou-lhe perceber que os participantes alcançaram domínios mais expressivos do conteúdo quando resolveram o problema proposto de modo colaborativo (BARATO, 2008, p. 6).

Com resultados desse tipo, a WebQuest tem possibilitado o uso da internet voltado à produção de conhecimentos mais complexos e bem elaborados (JUNIOR e COUTINHO, 2009, p. 107). Sua aplicação pode ser de curta ou longa duração: no primeiro caso, o objetivo é a integração dos conhecimentos já que os estudantes interagem com um número mais restrito de informações. É uma ação planejada para um período máximo de três aulas. No segundo caso, os estudantes são conduzidos por um percurso mais profundo, dentro de um conjunto de conhecimentos que requerem raciocínios mais consistentes e duradouros. Pode ter duração de até um mês de trabalho escolar (DODGE, 1996, p. 1-2).

Evitar a "surfagem", ou seja, quando os estudantes navegam pela internet sem critérios muito claros de seleção e uso das informações, é uma das principais contribuições desta metodologia, composta, em seu formato clássico, de cinco elementos: (1) a introdução, etapa em que o estudante identifica o conteúdo a ser trabalhado; (2) a tarefa, em que ele toma conhecimento do tipo de produção (teatro, vídeo, poema, paródia, etc.) a ser desenvolvida e o personagem a ser interpretado; (3) o processo, durante o qual são apresentados os dados necessários para executar a tarefa (podem ser links de vídeos, sites da internet, docu- 
mentos históricos digitalizados, mapas, tabelas, fotos, etc.); (4) a avaliação, que apresenta os critérios de análise de desempenho a serem aplicados ao produto requerido pela atividade; e (5) a conclusão, que estimula a continuidade do aprendizado sobre a temática tratada na WebQuest (DODGE, 1996, p. 1-2). Nesta é possível apresentar sugestões de materiais complementares. ${ }^{2}$

$\mathrm{Na}$ história escolar brasileira, as investigações sobre WebQuest ainda se encontram em estágio inicial. Por ora, existe um número restrito de autores com iniciativas relevantes sobre o tema ${ }^{3}$ e, como reflexo disso, há muitas lacunas a serem preenchidas com base em questões da nossa realidade.

Perante esse quadro, chamaram-nos a atenção os resultados da pesquisa de Adaiane Giovanni: ela aplicou a WebQuest em turmas do Ensino Médio e isso lhe permitiu mapear diferentes níveis "de compreensão e de abordagem [...] dos alunos em relação ao tema proposto", o que evidencia o potencial da metodologia "quanto à promoção da aprendizagem significativa" (2016, p. 102).

Esses ditos níveis de “compreensão" e de "abordagem” são parte das estratégias e articulações empregadas pelos sujeitos com a finalidade de aprender História. Ao tentar compreendê-las, passamos a indagar como a metodologia estudada favorece a aprendizagem da matéria. Para tanto, a análise das produções dos estudantes foi o caminho escolhido para verificar se a WebQuest possibilita a elaboração de produções com níveis significativos de apropriação do conteúdo ensinado.

Ao nos debruçarmos sobre o problema, o conceito de "competência narrativa" serviu-nos de ponto de partida para aprofundar as reflexões inicialmente formuladas. Ela pode ser caracterizada "como a habilidade da consciência humana para levar a cabo procedimentos que dão sentido ao passado, fazendo efetiva uma orientação temporal" (RÜSEN, 2010b, p. 59). Em outras palavras, é a capacidade dos sujeitos de utilizar a história de forma coerente e contextualizada acionando o máximo possível suas contribuições e seus recursos interpretativos.

Segundo Jörn Rüsen, perante os contratempos da vida cotidiana, existe a necessidade de se empregar a capacidade de argumentar historicamente. Quando, em meio a esse procedimento, o processo cognitivo possibilita o "reforço da capacidade de inserir e utilizar interpretações históricas" (2007, p. 110), pode-se falar em competência narrativa. E ampliar a capacidade dos sujeitos de construir narrativas históricas configura-se como uma das atribuições 
primordiais do ensino de História. Por meio dele, a consciência histórica ${ }^{4}$ pode ajudar a compreender, transpor ou, quando necessário, realizar oposição a determinados limites do senso comum.

Na perspectiva de Rüsen, o conceito de competência é formado por três elementos: (i) a competência para a experiência histórica é a capacidade de lidar com as diferentes temporalidades; assimilar as contribuições de ler o passado e, ao mesmo tempo, diferenciá-lo do presente. É conseguir estabelecer temporalmente a barreira entre o "eu" e o "eles", o período em que estamos vivendo e o período em que os outros viveram (RÜSEN, 1992, s. p.); (ii) a competência para a interpretação histórica é a capacidade de articular passado, presente e futuro dentro de uma trama explicativa com potencialidade de orientação de nossas ações na cena contemporânea. Ela se manifesta quando somos forçados a romper com as limitações do pensamento cotidiano e buscar na História a ampliação das nossas expectativas e capacidades de explicar o mundo (RÜSEN, 1992, s. p.); (iii) a competência de orientação histórica está relacionada ao potencial de tomar decisões recorrendo aos ganhos produzidos pela reflexão gerada por uma leitura mais habilidosa do todo temporal: presente, passado e futuro. Em outros termos, significa "guiar a ação por meio das noções de mudança temporal, articulando a identidade humana com o conhecimento histórico, mesclando a identidade no enredo e na própria trama concreta do conhecimento histórico" (RÜSEN, 1992, s. p.).

Contudo, Sant et al., ao referirem-se às contribuições de Rüsen e de Arthur Chapman para pensar a competência narrativa, destacam que eles "oferecem uma excelente orientação geral para a análise de narrativas e competência narrativa, mas não são específicos para analisar a estrutura das narrativas". Em contraste, ao mencionar os escritos de Jocelyn Létourneau e Ferran Grau Verge, os dois "se concentram mais claramente nos elementos estruturais, mas eles perdem a concepção holística da narrativa” (2014, p. 168, tradução nossa). Enfrentar essas questões teóricas exigiu um olhar específico sobre a produção do conhecimento histórico ${ }^{5}$ por meio de atividades colaborativas como a WebQuest. ${ }^{6}$

Segundo Patrícia Lupion Torres e Esrom Adriano Freitas Irala (em referências às ideias de Pierre Dillenbourg), atividade colaborativa é "uma situação de aprendizagem na qual duas ou mais pessoas aprendem ou tentam aprender algo juntas". Na visão dos autores, trata-se de um conceito que engloba "situa- 
ções de aprendizagem presenciais ou virtuais, síncronas ou assíncronas, esforço totalmente em conjunto ou com divisão de tarefas" (2014, p. 65). Devido às suas particularidades, as práticas educacionais colaborativas mediadas pelo uso de tecnologia têm cobrado uma releitura das concepções epistemológicas e didático-pedagógicas concernentes ao ato educativo, sobretudo por conta do surgimento de "novas perspectivas para os processos de ensinar e aprender" (SPAGNOLO e MANTOVANI, 2013, p. 8).

Assim, com enfoque na atividade colaborativa mediada pelo uso da metodologia WebQuest para o ensino de História, as contribuições teóricas de Paul Ricoeur sobre o conceito de narrativa possibilitaram refletir sobre essa tipologia de produção do conhecimento escolar. Este autor entende a narrativa como um gênero particular de discurso pautado em processos que envolvem a invenção de uma intriga (1994, p. 9-10), caracterizada por uma "atividade de síntese realizada pelo seu produtor-autor, através de um processo ativo de interpretação", que pode reunir "sob uma unidade temporal, elementos heterogêneos", ou seja, nos múltiplos personagens inspirados ou não em fragmentos de experiências vividas (AXT et al., 2001, s. p.). Movimento que dá vida a uma narrativa marcada por tramas comparativas, entendimentos, discordâncias e conexões entre objetos, lugares e personagens. Neste horizonte, para Margaret Axt et al., uma produção colaborativa pode consubstanciar-se em uma intensa dinâmica em que embates, negociações e ajustamentos descortinam a citada intriga, com a qual os indivíduos nela envolvidos forjam a narrativa (2001, s. p.).

Em decorrência disso, se considerarmos que as produções colaborativas são tramas complexas, chegar ao nível das especificidades da consciência histórica, como alguns pesquisadores têm feito ao estudarem as narrativas escolares, ${ }^{7}$ exigiria o abandono de alguns propósitos deste trabalho. Logo, a competência narrativa, nos termos levantados até esse ponto, nos serve de parâmetro para pensar a relação entre a WebQuest do estudo e as produções dos estudantes ${ }^{8}$, estratégia empregada para compreender o percurso de resolução da tarefa realizada por eles. Para sustentar essa abordagem recorremos ao trabalho de Sant et al. (2014). Nele, os pesquisadores analisaram 78 textos sobre a História da Catalunha produzidos por estudantes do Ensino Secundário Obrigatório (ESO) e do $1^{\circ}$ de Bachillerato de seis centros distintos da Ca- 
talunha. Utilizamos 14 das questões ${ }^{9}$ (ver Quadro 2) aplicadas nesse estudo específico.

Quadro 1 - Instrumento de análise de competência narrativa

\begin{tabular}{|c|c|}
\hline \multicolumn{2}{|c|}{ É UMA NARRAÇÃO? } \\
\hline $\mathbf{1 .}$ & O texto é uma sequência de eventos relacionados por meio de uma trama? \\
\hline $\mathbf{2 .}$ & O narrador usa um tempo mais narrativo além do tempo cronológico? \\
\hline \multicolumn{2}{|c|}{ COMO ESTÁ O CONTEÚDO? } \\
\hline $\mathbf{3 .}$ & O texto contém informações do tipo histórico? \\
\hline $\mathbf{4 .}$ & Os fatos históricos da narrativa são fatos contrastados? \\
\hline $\mathbf{5 .}$ & O texto sugere uma consciência histórica, crítica ou genética? \\
\hline $\mathbf{6 .}$ & COMO ESTÁ A ESTRUTURA? \\
\hline 7. & A narrativa tem um resumo ou um título? \\
\hline $\mathbf{8 .}$ & A narração está localizada no tempo? \\
\hline $\mathbf{9 .}$ & A narração está localizada no espaço? \\
\hline $\mathbf{1 0 .}$ & O narrativa tem personagens? Quem são eles? \\
\hline $\mathbf{1 1}$ & A história contém um desfecho? \\
\hline $\mathbf{1 2}$ & A narrativa contém uma perspectiva do futuro? \\
\hline $\mathbf{1 3}$ & A avaliação é inerente aos eventos mencionados? \\
\hline $\mathbf{1 4}$ & A narrativa tem um tema dominante? \\
\hline
\end{tabular}

Fonte: (Sant et al., 2014, p. 177, tradução nossa).

Ao aplicar tais questões, havia dois objetivos específicos: (1) entender como os estudantes desenvolvem o percurso proposto pela metodologia $\mathrm{We}$ bQuest; (2) avaliar seus limites e possibilidades na disciplina de História. Em razão da problemática e dos objetivos da presente pesquisa, desenvolvemos uma WebQuest de curta duração, que foi aplicada entre os meses de julho e outubro de 2018 em um grupo de 85 estudantes do $8^{\circ}$ ano do Ensino Fundamental e $2^{\circ}$ ano ${ }^{10}$ do Ensino Médio. Matriculados em quatro turmas do Colégio Estadual Adonis Morski - EFMP (CEAM), estabelecimento de ensino público da cidade de Boa Ventura de São Roque, Paraná.

De maneira geral, os resultados obtidos não foram como esperado. Con- 
tudo, possibilitaram contemplar pontos relevantes sobre a aplicação da WebQuest à disciplina de História. Eles serão explorados mais adiante, porém, sem se recorrer a todas as questões do Quadro 2, pouco contempladas nas produções do grupo investigado.

\section{A WEBQUEST DO ESTUDO}

A WebQuest desta investigação, intitulada "A presença dos escravos ${ }^{11}$ nas fazendas do Paraná - século XIX”, foi hospedada no site Janela para a História (http://janelaparaahistoria.unespar.edu.br/), da Universidade Estadual do Paraná/UNESPAR, criado em 2013 e, desde então, coordenado pelo professor Fábio André Hahn. O tema principal é a revolta de escravizados de 1864, ocorrida em Castro/PR, um reflexo do tráfico interprovincial que forçou diversos escravizados desse lugar a se mudarem para outras regiões do Brasil.

\section{Imagem 1 - Caso: a presença dos escravos}

nas fazendas do Paraná - século XIX

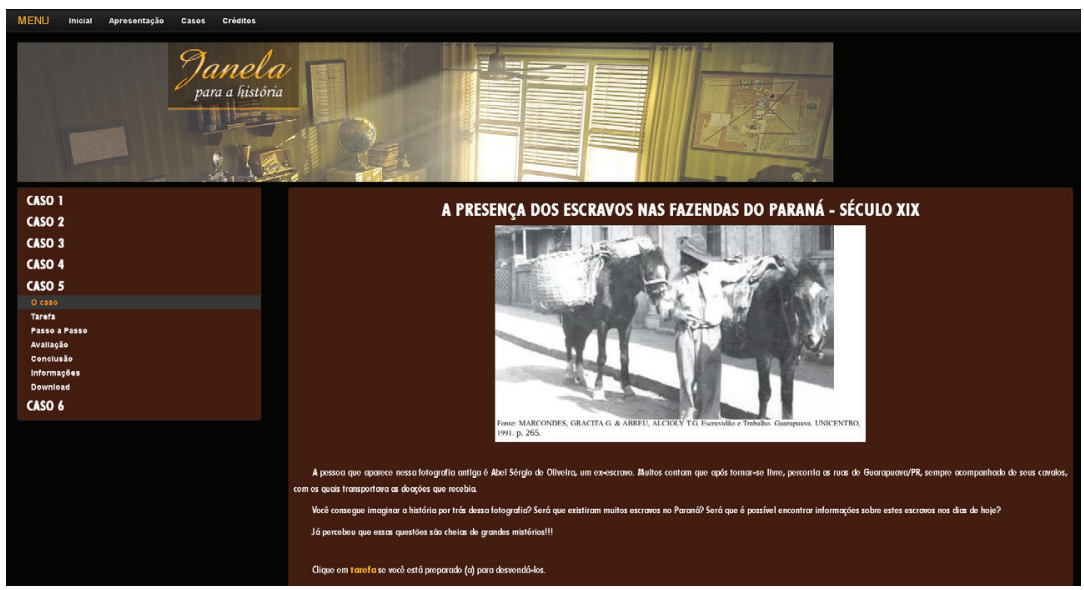

Fonte: http://janelaparaahistoria.unespar.edu.br/

$\mathrm{Na}$ "introdução", intitulada "o caso" na WebQuest aplicada (ver Imagem 1), apresenta-se uma fotografia de um ex-escravizado da cidade de Guarapuava/PR, Abel Sérgio de Miranda. Três perguntas foram atreladas à análise dessa imagem: "Você consegue imaginar a história por trás desta fotografia? Será 
que existiram muitos escravizados no Paraná? Será que é possível encontrar informações sobre esses escravizados nos dias de hoje?”.

Na seção seguinte, os estudantes se depararam com esta "tarefa", do tipo compilação: ${ }^{12}$

Primeiro, imagine que você é um pesquisador famoso e que está pesquisando o tema "Escravidão no Paraná". Por esse motivo, tem feito várias viagens, coletado informações e entrevistado pessoas. Depois de alguns meses de muito trabalho, para sua surpresa recebeu um convite do jornal Diário Paranaense para que escrevesse um relato explicando as características da escravidão que existia no Paraná. Esse relato será publicado na página principal do jornal. Sabendo que muita gente vai ler o texto, sua primeira reação foi positiva, e você pensa: "Tenho que caprichar, pois é uma ótima oportunidade de mostrar aos leitores do jornal o que eu já descobri sobre um tema ainda pouco conhecido pela maioria das pessoas". (HAHN e NASCIMENTO, 2018, s. p.)

Mais especificamente, no "passo a passo", denominado de "processo" na terminologia de Dodge, foram disponibilizadas três seções: "pista 1", "pista 2" e "pista 3", conforme pode ser observado na Imagem 2.

\section{Imagem 2 - Caso: a presença dos escravizados}

nas fazendas do Paraná - século XIX

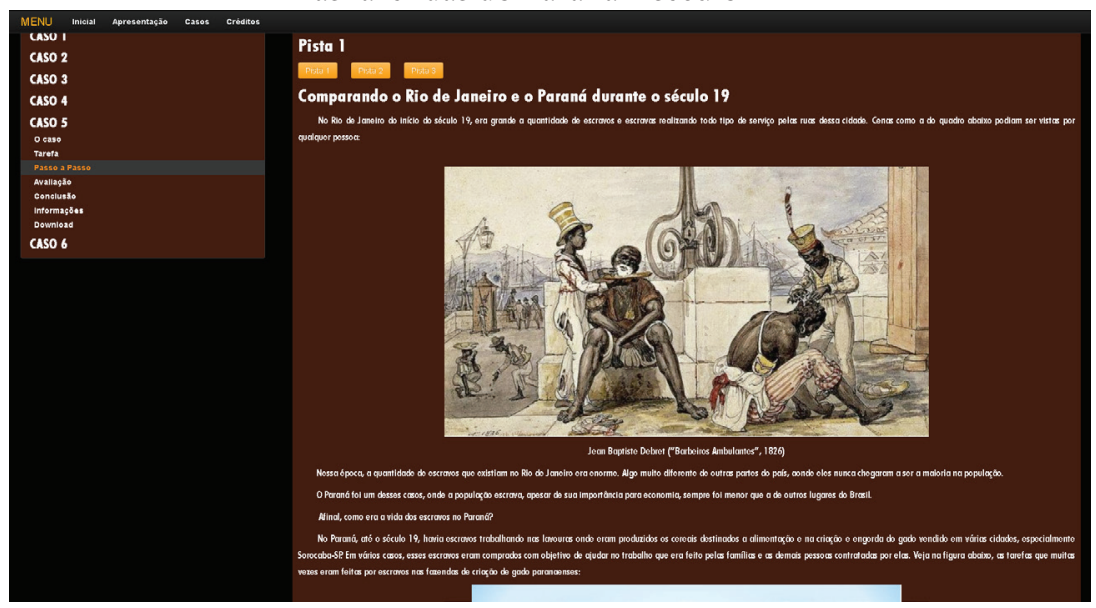

Fonte: http://janelaparaahistoria.unespar.edu.br/ 
Em síntese, na "pista 1" constavam informações alusivas ao século XIX acerca da escravidão no Rio de Janeiro em comparação com a do Paraná, com o objetivo de destacar características do escravismo praticado neste último estado. Na "pista 2", ao recorrer a dados publicados pelo historiador Horácio Gutierrez (2006, p. 103), apresentamos a configuração quantitativa da escravaria em diferentes fazendas paranaenses até o ano de 1818. Finalmente, na "pista 3", a seção mais extensa, trabalhou-se a história da revolta escrava em Castro/PR.

\section{Imagem 3 - Caso: a presença dos escravizados}

nas fazendas do Paraná - século XIX

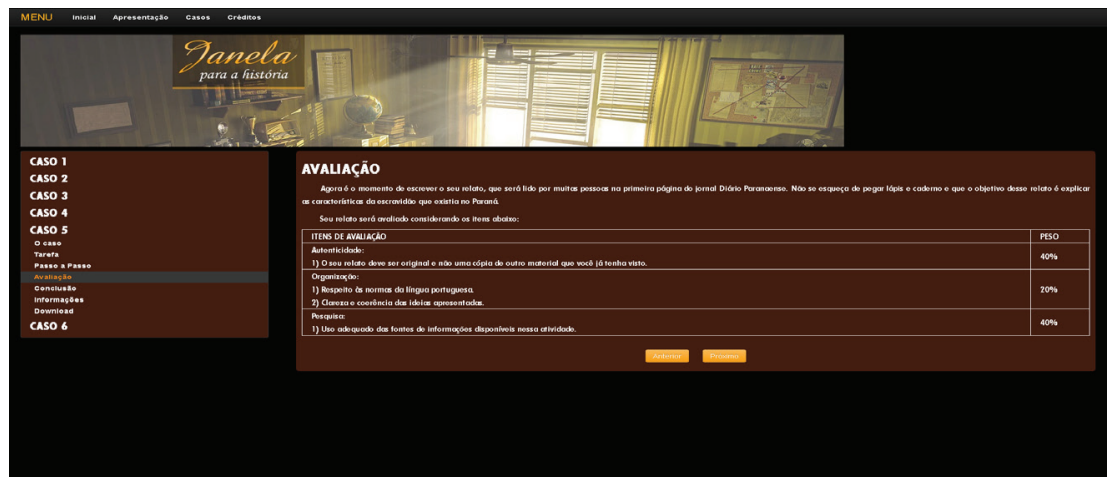

Fonte: http://janelaparaahistoria.unespar.edu.br/

A “avaliação" (ver Imagem 3), uma das partes centrais da atividade, foi estruturada de acordo com os seguintes critérios: autencidade, organização e pesquisa.

\section{ANÁLISE DOS RESULTADOS}

A atividade requerida dos estudantes - um relato a ser publicado num jornal - resultou em 36 produções textuais. Elas foram analisadas em dois níveis, de acordo com os critérios arrolados na seção "avaliação" da WebQuest aplicada: ${ }^{13}$ primeiro, a coerência textual e uso adequado dos recursos da língua portuguesa; segundo, o tratamento das informações disponibilizadas. Nesta parte, conforme já discutimos anteriormente, o enfoque recai sobre a competência narrativa. 
Em síntese, no tocante ao primeiro nível, considerável parte das produções apresentou usos inadequados dos recursos da língua formal e, além disso, continham "cópias literais" misturadas a pequenos trechos dotados de originalidade. Também houve um caso de plágio de texto do site Wikipédia. No segundo eixo, abordamos as produções nos três níveis - narração, conteúdo e estrutura - em conformidade ao esquema proposto no estudo desenvolvido por Sant et al. (2014) (ver Quadro 1).

\section{NARRAÇÃO}

O texto é uma sequência de eventos relacionados em uma trama? Segundo o linguista Yves Reuter, toda história depende do desenvolvimento de uma narrativa. Existem, porém, dois grandes “modos narrativos” para fazê-lo: o contar e o mostrar. O primeiro refere-se à narrativa em que o autor é visível, ou seja, não dissimula nem apaga intencionalmente sua presença. $\mathrm{O}$ segundo diz respeito à construção do ato narrativo com marcas de discurso indicativo de uma proximidade maior dos eventos, como se aqueles que narram estivessem próximos a eles (2002, p. 60).

O contar apresenta uma "clara tendência ao resumo e se caracteriza por uma visualização menor" de características do objeto narrado, enquanto o ato de mostrar contém passagens mais construtivas e caracteriza-se pela presença de falas mais diretas e excesso de detalhes (REUTER, 2002, p. 60-61).

As narrativas de $8-\mathrm{X}+8-\mathrm{H}$ e $2-\mathrm{M}+2-\mathrm{K}$ em sua maioria adotam a tipologia do contar, isto é, os estudantes demonstram menor envolvimento do narrador com os eventos veiculados pela WebQuest. Por exemplo:

\section{8-X 9}

\section{Escravidão em Capão Alto}

A escravidão começou quando a comunidade carmelita comprou a fazenda Capão Alto. Ela localizava-se na rodovia de Viamão a Sorocaba. Após os carmelitas irem embora, quem administrava a fazenda eram os escravizados que lá viviam, por isso, os escravizados criaram uma comunidade independente (um quilombo) e lá cultivavam alimentos para seu consumo e para fazer troca de alimentos com os tropeiros que por ali passavam.

Apesar de uma pequena população de escravizados, no Paraná exerciam papeis importantes na administração, na construção e cuidar dos animais e plantações. 
Muitos fazendeiros não moravam em suas fazendas então tinham que confiar em alguns escravizados.

No século 19 era muito difícil trazer mão de obra da África, então tiveram que encontrar escravizados em outras regiões do Brasil. E nessa época os carmelitas arrendaram a fazenda Capão Alto trazendo enorme preocupação aos escravizados que lá moravam, pois receberam a notícia que perderiam sua liberdade, então se preparam para lutar, pois não aceitaram a ideia de deixar a fazenda e estavam dispostos a permanecer ali. Então chamaram a policia que colocou fim a revolta.

\section{2-K 1}

Sem título

A presença dos escravizados no Paraná era de grande diferença comparada a do Rio de Janeiro.

No Rio de Janeiro era grande a quantidade de escravizados que realizavam todo tipo de trabalho pelas ruas da cidade. Em outros países do mundo, os escravizados nunca chegaram a ser maioria da população.

O Paraná foi um desses casos, onde os escravizados apesar de sua importância, sempre foi menor que a de outros lugares do Brasil. Os escravizados trabalhavam nas lavouras e produziam os cereais para alimentação, trabalhavam também na criação, engorda do gado vendido em várias cidades, especialmente em São Paulo. Uma das cidades que possuía grande quantidade de escravizados no Paraná era Castro que tinha 121 fazendas com 758 escravizados.

Alguns padres carmelitas cuidaram de uma fazenda Castro, mas depois foram embora e os escravizados assumiram. Durante a segunda metade do século $19 \mathrm{o}$ fim da escravidão dificultou a mão de obra do africano que em 1864, os padres arrendaram a fazenda.

Tanto em 8-X 9 quanto em 2-K 1 existem pequenos erros de ordenamento cronológico e trato de informações da WebQuest, padrão reproduzido em várias produções. É perceptível igualmente, o fato de as narrações terem adotado o uso da terceira pessoa, sem expressar um envolvimento mais direto do narrador com a informação transmitida.

No entendimento de Ricoeur, o "tempo torna-se tempo humano na medida em que está articulado de modo narrativo; em compensação, a narrativa é significativa na medida em que esboça traços da experiência temporal" (1994, 
p. 15). Em função disso, as vivências sociais dos indivíduos em relação àquilo que eles narram são parte relevante do processo de construção do sentido.

De uma perspectiva narratológica, ${ }^{14}$ pode-se abordar uma informação ao considerar o "ponto de vista de sua organização, de sua construção formal, dos conteúdos apresentados" e, não menos importante, seu espectro de enunciação (REUTER, 2002, p. 9-10). Seguindo essa lógica, os seguintes questionamentos são aplicáveis: "Quem escreveu? Com qual finalidade? A quais traços os sujeitos atribuem maior importância sobre o período abordado?”. E o mais relevante para a presente pesquisa: "Como eles interagem com as informações contidas na atividade?". Pontos que possibilitam o entendimento do processo por meio do qual os estudantes desenvolveram a tarefa.

O narrador usa um tempo mais narrativo além do tempo cronológico? $\mathrm{Na}$ produção de uma narrativa histórica, ${ }^{15}$ não basta ter a capacidade de elaborar uma trama orientada pela cronologia e memória dos acontecimentos passados. Saber materializá-la narrativamente é parte do processo de sua inserção nas questões da vida social humana. Este processo não é fechado no ato de escrever um texto, pois depende de raciocínios e de estratégias que vão além do ato de produção textual, já que dialogam com várias experiências sociais dos sujeitos. Dito de outro modo, não basta somente saber a ordem dos fatos, é necessário abordá-los dentro de uma narrativa que os conecte e lhes dê sentido, sem reduzi-los a apenas uma lista de acontecimentos sobre o passado. Procedimento, quando mobilizado pelos estudantes, dependente de certo exercício de criatividade.

Nesta dimensão, mesmo com a presença pequena de textos compatíveis com as especificidades de uma publicação direcionada a leitores de um jornal, como era requerido pela tarefa, os dados indicam que a metodologia WebQuest contribuiu para a elaboração de relatos com graus de inventividade em certa medida perceptíveis, ${ }^{16}$ apesar de pouco refinados no campo de tratamento das informações históricas.

\section{CONTEÚDO}

Os fatos históricos da narrativa são fatos contrastados? Os dados analisados evidenciam a inexistência de produções do grupo 8-X+8-H que questionassem, complementassem, relessem ou propusessem interpretações alternativas ao tema abordado na WebQuest. 
Ocorreu, contudo, que os integrantes de $8-\mathrm{X}+8-\mathrm{H}$, em sua maioria, realizaram a atividade sem fazer caminhos adicionais marcados pelo diálogo com outros tipos de informação. Acreditamos que a ausência de explorações que fossem além da narrativa da WebQuest tenha ocorrido pela dificuldade de ler, interpretar e seguir os comandos propostos, ou até pela ausência de engajamento pessoal e coletivo, devido às características da produção requerida.

De maneira especial, “o conteúdo de ensino é o elemento central que movimenta esse cenário fundado e emoldurado pela metodologia" (AMARAL, 2006, p. 10). Como reflexo disso, mesmo o aporte metodológico ocupando um lugar específico na construção do conhecimento, outros fatores ligados ao tratamento do conteúdo ensinado precisam ser levados em consideração.

Apesar do boom da internet, com relativo nível de imersão na vida das crianças e dos adolescentes da atualidade, ao solicitar de $8-\mathrm{X}+8-\mathrm{H}$ um relato para jornal, presumimos que não seria uma situação difícil de ser imaginada pelos estudantes. Todavia, os resultados não foram satisfatórios. Em especial, a proposição de assumir o papel de um pesquisador famoso prestes a publicar um texto no jornal fictício Diário Paranaense mostrou-se algo muito distante dos referenciais de vida dos estudantes, até porque saber claramente as atribuições e rotinas típicas desse profissional depende de um conjunto de pré-conhecimentos consolidados.

Desse modo, é sempre bom recorrer a situações mais significativas que envolvam personagens ou problemas vivenciados pelos estudantes ou que eles conheçam. Talvez situações em que padeiros, leiteiros, entregadores de jornal e todo tipo de profissionais, grupos e indivíduos mais familiares aos educandos solucionem problemas cotidianos com base em conteúdos históricos. Sob outra perspectiva, desde que bem alinhado com referências de vida dos estudantes, também é válido o esforço de colocá-los diante de situações históricas do passado que mobilizem suas imaginações.

Mais especificamente no grupo 2-M+2-K, um dos poucos casos de produções com a ocorrência de informações contrastantes é 2-M 5, citado abaixo:

\section{Escravidão}

Todos nós temos o conhecimento básico sobre o que é a escravidão, "como surgiu", "como funcionou". Então, vamos sair do básico e ter mais conhecimento sobre este assunto? 
Muitos pensam que apenas os índios foram vítimas da escravidão, mas na verdade a maioria dos escravizados veio de fora, da África.

Eles eram trazidos para a capital, que na época era o Rio de Janeiro, e dali eles eram divididos, selecionados para irem para outros estados e, assim, vendidos. Geralmente, os escravizados iam para as fazendas, para poderem trabalhar lá, e assim fornecer lucro para a mesma.

O Paraná é um bom exemplo para pegarmos. Lá eles faziam desde alimentar os animais até domar os cavalos, fazer a queimada do pasto, matar e preparar as carnes dos animais, preparar o couro para fabricação..., entre outros serviços.

No Paraná, o lugar onde mais tinha escravizados era Castro, com aproximadamente 121 fazendas, com 758 escravizados.

O relato produzido segue o percurso de uma apresentação geral do tema escravidão aos seus leitores. Busca, no entanto, em seus últimos parágrafos, conectar a experiência do escravismo paranaense a um contexto maior, o do tráfico escravista. Ademais, na elaboração da trama discursiva, 2-M 5 observa: "Muitos pensam que apenas os índios foram vítimas da escravidão, mas na verdade a maioria dos escravizados veio de fora, da África”. A temática da escravização indígena não fazia parte da WebQuest; sem dúvida, trata-se de um apêndice ao assunto abordado. Mencionar o fato de muitas pessoas pensarem que só houve escravidão indígena, ao ponto de deixarem de lado a experiência africana não deixa de ser um tipo de complemento a determinada intepretação histórica tida como recorrente em algum espaço da sociedade. Outro aspecto a ser observado é o das partes do texto alusivas às tarefas realizadas pelos escravizados e à quantidade deles nas fazendas de Castro. Trata-se de informações que apareceram na mesma sequência disposta na WebQuest. Esse padrão foi repetido vezes seguidas por quase todos os estudantes, o que conduz à reflexão sobre o processo de conexão e uso das informações do exercício desenvolvido.

Em atividades na internet sem parâmetros de pesquisa preestabelecidos, sempre existe o risco de os estudantes "se perderem" em meio à torrente de informações disponibilizadas e caírem nos perigos da navegação sem rumo pela rede mundial de computadores. No caso da WebQuest, quando as pistas não são devidamente integradas para exercer um diálogo mais preciso e construtivo entre si, existe uma tendência de serem empregadas de modo excessi- 
vamente instrumental. Dito de outro modo, os estudantes podem vir a dispensar parte das "pistas", vir a tratá-las como se não fizessem parte do todo ou, pior ainda, nem ao menos lê-las cuidadosamente.

Como propõe José Manuel Moran, a aprendizagem ganha maior relevância para os estudantes quando eles veem sentido nela e suas motivações pessoais são acionadas para a resolução da atividade proposta (2017, s. p.). Em relação a esse item específico, cabe o alerta de Dodge para a grande importância do perfil das tarefas propostas aos estudantes (1999, s. p.), responsáveis quando bem elaboradas - por acionar as "motivações profundas" necessárias para a sua realização. Aplicado à metodologia WebQuest, esse princípio cobra-nos o desenvolvimento de novas formas de compartilhamento, construção e reelaboração do conhecimento histórico.

\section{ESTRUTURA}

A narrativa tem um resumo ou um título? Tal questão dirige-se a aspectos formais dos textos produzidos. Neste eixo, observamos os títulos atribuídos, entendendo-os como recortes privilegiados dentro da temática estudada.

Quadro 2 - Título das produções dos estudantes

\begin{tabular}{|l|l|}
\hline \multicolumn{1}{|c|}{$\mathbf{8 - X + 8 - H}$} & \multicolumn{1}{c|}{ 2-M+2-K } \\
\hline - A escravidão em Capão Alto & - Escravidão (2) \\
- A escravidão no Paraná & - Escravidão no Paraná (3) \\
- Fatos sobre a escravidão no Paraná & - Escravizados \\
- Escravizados no Paraná & - Os escravizados do Paraná (2) \\
- Sobre a escravidão & - Fazenda Capão Alto e o tráfico \\
- A presença dos escravizados nas fazendas & interprovincial \\
do século XIX (3) & \\
\hline
\end{tabular}

Fonte: Dados da pesquisa.

Fora os casos de relatos sem título, a correlação entre ele e a ideia central de algumas produções mostrou-se fraca. Além disso, ocorreu a reprodução literal de títulos das seções da WebQuest implementada.

A narração está localizada no tempo? É notória a presença considerável 
de marcadores temporais nas tarefas produzidas por $8-\mathrm{X}+8-\mathrm{H}$ e $2-\mathrm{M}+2-\mathrm{K}$, conforme mostra o Quadro 3:

Quadro 3 - Marcadores temporais

\begin{tabular}{|c|c|}
\hline $8-\mathrm{X}+8-\mathrm{H}$ & $2-M+2-K$ \\
\hline $\begin{array}{l}\text { - O século da escravidão foi difícil [...]. } \\
\text { - Durante a metade do século XIX, o fim do } \\
\text { tráfico de escravizados preocupava muitas } \\
\text { pessoas [...] (3). } \\
\text { - No Paraná até o século XIX havia } \\
\text { escravizados nas lavouras [...]. } \\
\text { - No século XIX havia uma diferença entre } \\
\text { Rio de Janeiro e Paraná [...]. } \\
\text { - Então após o século XIX chega o fim da } \\
\text { escravidão no Paraná [...]. } \\
\text { - No século XIX era muito difícil trazer mão } \\
\text { de obra da África [...]. } \\
\text {-No século XIX, era grande a quantidade de } \\
\text { escravizados no Rio de Janeiro [...]. } \\
\text { - Por volta do século XIX, a escravidão era } \\
\text { em grande quantia, todos os escravizados } \\
\text { realizavam todo tipo de serviço... No século } \\
\text { XIX, muitos proprietários não moravam } \\
\text { em suas próprias fazendas. }\end{array}$ & $\begin{array}{l}\text { - Em } 1751 \text { na Fazenda Capão Alto [...]. } \\
\text { - Há cinco anos comecei uma pesquisa na região } \\
\text { sul [...]. } \\
\text { - No século XIX, era grande a quantidade de } \\
\text { escravizados que faziam todo serviço da cidade do } \\
\text { Rio de Janeiro [...]. (2) } \\
\text { - Até o século XIX no Paraná, os escravizados } \\
\text { eram direcionados a trabalhar em lavouras. } \\
\text { - No Paraná no século XIX, havia escravizados } \\
\text { trabalhando nas lavouras [...]. } \\
\text { - Hoje em dia tem casos de escravidão, mas é } \\
\text { muito pouco [...]. } \\
\text { - A escravidão iniciou em 1530, os primeiros } \\
\text { escravizados foram os indígenas. No Paraná havia } \\
\text { escravizados trabalhando no século XIX [...] } \\
\text { - Na metade do século XIX, o fim do tráfico de } \\
\text { escravizados começou a preocupar muitos } \\
\text { fazendeiros [...] } \\
\text { - No Paraná e em diversas regiões do Brasil, o } \\
\text { tráfico de escravizados teve sua importância para } \\
\text { a economia até o século XIX, muitos escravizados } \\
\text { ainda eram vistos nas fazendas [...]. } \\
\text { - Na metade do século XIX houve o fim da } \\
\text { escravidão e com isso ocorreu prejuízo para a } \\
\text { safra [...]. } \\
\text { - No século XIX, período de maior atividade do } \\
\text { tropeirismo [...]. } \\
\text { - Os escravizados no Paraná eram submetidos a } \\
\text { trabalhar nas fazendas, isso no século XIX [...]. }\end{array}$ \\
\hline
\end{tabular}

Fonte: Dados da pesquisa.

Em 2-M+2-K ocorre o destaque de aspectos e temas que não foram mencionados na WebQuest ou até a releitura de alguns assuntos nela registrados. Nas duas condições, foram contemplados temas do tipo: a safra, a escravidão indígena, o período de maior desenvolvimento do tropeirismo e 
as más condições de trabalho na atualidade (escravidão). Estas formulações evidenciam "configurações pré-narrativas da ação". ${ }^{17}$ Diante delas, o fato de os estudantes terem feito algumas elaborações criativas no tratamento dos marcadores temporais, ainda que com a presença de cópias literais da WebQuest, indica a presença de conhecimentos mais locais, como, por exemplo, sobre a safra.

Nesse universo, chama a atenção o caso de 2-M 4, que, ao incorporar o personagem requerido pela tarefa, um pesquisador famoso, apresenta a seguinte elaboração narrativa: "Há cinco anos comecei uma pesquisa na região sul", uma elaboração discursiva no tempo passado. Pelo lado oposto, 2-M 3, com olhar fito no presente, assevera, "Hoje em dia tem casos de escravidão, mas é muito pouco". No entanto, diferentemente, quanto aos marcadores temporais do grupo 8-X+8-H, predominou a reprodução de diversos fragmentos da We$b$ Quest aplicada.

O narrador avalia a informação? Os eixos coerência avaliativa e coerência temática são parte desta questão. O primeiro está relacionado à capacidade de construção de uma trama com nexos consistentes de causa e efeito. É saber posicionar-se sobre determinado assunto histórico sem se perder diante das muitas possibilidades de abordá-lo historicamente. Os dados deste estudo são, contudo, poucos expressivos para defender, de maneira conclusiva, que a coerência avaliativa seja um traço dominante nas produções estudantis, tanto do grupo $8-\mathrm{X}+8-\mathrm{H}$ quanto do $2-\mathrm{M}+2-\mathrm{K}$, porque são poucos os casos denotativos de coerência avaliativa dentro do conjunto de produções analisadas. Em meio a esses poucos casos, podem ser escolhidos, por exemplo, os seguintes:

\section{2-K 5}

\section{Escravidão no Paraná}

Caros leitores, hoje nós vamos abordar o assunto da escravidão no Paraná, embora não tenha muita informação, e as pessoas em sua maioria acham que não tenha ocorrido em nosso estado estamos aqui para esclarecer esse assunto.

O Paraná é um caso onde a população de escravizados foi pequena se comparada com a de outros estados, apesar de sua importância econômica. 


\section{8-H 4}

\section{Sem título}

Nesta pesquisa percebemos que o século da escravidão foi difícil para os negros. E, ao comparar o Rio de Janeiro com o Paraná, percebemos que no Rio tinha muito mais escravizados. Apesar de não sermos capazes de estabelecer uma média.

Castro era a cidade do Paraná que possuía maior quantidade de escravizados. Quantos escravizados será que existiram no Rio de Janeiro?

Em contrapartida, a coerência temática está relacionada à capacidade de se manter num gênero dominante (de quadrinhos a peças de teatro) sem abandonar a centralidade do elemento histórico. Esse aspecto narrativo, no entanto, pouco aparece dentro do conjunto geral das produções.

A história contém um desfecho? Quanto a esse ponto, os relatos seguem uma tendência já observada: a mesma sequência das pistas da WebQuest. Tanto em $8-\mathrm{X}+8-\mathrm{H}$ quanto em $2-\mathrm{M}+2-\mathrm{K}$, os parágrafos finais dos relatos, em sua maioria, repetem na íntegra trechos da última parte da atividade desenvolvida.

\section{CONSIDERAÇÕES FINAIS}

Os resultados apresentados permitiram-nos observar diversas questões concernentes à metodologia WebQuest, e à relação entre o uso das tecnologias e o protagonismo dos estudantes. Neste universo, a forma como o grupo investigado realizou a tarefa, possibilitou-nos perceber os seguintes aspectos: (a) a presença de reprodução da mesma rotina de outros exercícios e tarefas realizadas sem a utilização da internet; ${ }^{18}$ (b) poucas evidências de familiaridade com a resolução de situações-problema, ${ }^{19}$ particularmente as que envolvem percursos de navegação pelo ciberespaço; (c) dificuldade de integração das diferentes seções e das informações históricas da atividade desenvolvida.

Ao propor a tarefa, quando o comando é "consulte suas anotações", o estudante deveria se deparar com enunciados curtos; porém, a WebQuest utilizada adotou o formato de texto didático, em que o narrador questiona e conduz o "pesquisador" (personagem interpretado pelos estudantes na atividade). E isso facilitou o exercício de fazer recortes ou cópias literais, de forma que muitas produções não tiveram autenticidade. Quem sabe se a atividade 
fosse uma entrevista com perguntas lançadas previamente, esse problema poderia ser amenizado.

É perceptível, neste mesmo item, o fato de a tipologia de tarefa no formato compilação ter se mostrado insatisfatória, sobremaneira porque ela requereu dos estudantes o exercício de coletar, sintetizar e refinar a informação apresentada, levando-os a uma abordagem pouco inovadora da temática estudada. Nestas circunstâncias, as tarefas do tipo mistério ${ }^{20}$ ou criativa ${ }^{21}$ nos parecem mais adequadas ao ensino de História na educação básica, pois exigem maior envolvimento intelectual com as informações do exercício e, de certo modo, quando a preocupação diz respeito à originalidade dos trabalhos produzidos, em tese, podem oferecer um risco menor de que a atividade tome uma direção inesperada.

Outro ponto, igualmente observado por Giovanni (2016, p. 104), diz respeito à dificuldade dos estudantes em relacionar imagem (mapas, quadros) $\mathrm{e}$ texto veiculados na WebQuest. Em função disso, ao planejar a "tarefa" e o "processo", a correlação entre as informações imagéticas e as textuais merece uma atenção especial.

Fora isso, há o fato de os estudantes terem demonstrado diferentes formas de organização do trabalho colaborativo. Por esse motivo, a importância de combinar a citada metodologia com outras estratégias de ensino, sobretudo devido aos educandos com dificuldade de concentração, indisciplina e menor desempenho acadêmico. Em tais circunstâncias, para a disciplina de História e sua tendência a ser bastante "livresca e textual"22, aplicar WebQuests de curta duração pode ser uma boa iniciativa em turmas pouco receptivas a leituras mais extensas e complexas.

Quadro que cobra uma reflexão sobre cultura escolar, entendida aqui como o "conjunto de normas que definem conhecimentos a ensinar e condutas a inculcar, e um processo de práticas que permitem a transmissão dos conhecimentos" (JÚLIA, 2001, p. 10). Dentro dessa cultura, há sempre o risco de o uso das tecnologias ressuscitar velhas receitas disfarçadas de inovação somente por empregar recursos modernos (CYSNEIROS, 1998). Há, assim, a necessidade de se pensar o ensino de História com base nas interconexões entre as complexidades da escola pública, da aprendizagem histórica e da maneira que crianças e adolescentes interagem e dão sentido prático aos recursos tecnológicos do seu tempo. Em tal horizonte, da relação entre História e sujei- 
tos investigados, afloram questões ligadas às "formas de apresentação" do conhecimento histórico, segundo Rüsen, materializáveis nas produções (textos, músicas, jogos etc.) em que a ciência histórica adota uma linguagem acessível a todas as pessoas, mas sem perder sua validade científica (2010, p. 35-51). Ainda se deve considerar a dificuldade dos estudantes em áreas como leitura, escrita e interpretação, um grande problema do sistema educacional brasileiro - uma realidade vivenciada por grande parte dos professores, sobretudo aqueles que atuam em escolas públicas.

Por fim, apesar da necessidade de mais estudos comparativos, as produções do Ensino Médio foram levemente melhores que as do Fundamental. Este último, uma modalidade de ensino pouco contemplada no campo das investigações sobre tecnologia e educação, merece ser mais explorado pelos investigadores brasileiros (GIOVANNI, 2016, p. 105). Questão a ser considerada no desenvolvimento de pesquisas sobre a metodologia WebQuest e o ensino de História.

\section{REFERÊNCIAS}

ABAR, Celina Aparecida Almeida Pereira; BARBOSA, Lisbete Madsen. WebQuest um desafio para o professor: uma solução inteligente para o uso da internet. São Paulo: Avercamp, 2008.

AMARAL, Ivan Amorosino do. Metodologia do ensino de ciências como produção social. 2006. Disponível em: http://www.fe.unicamp.br/ensino/graduacao/downloads/proesfMetodologiaEnsinoCienciasIvan.pdf. Acesso em: 17 jul. 2014.

AXT, Margarete et al. Era uma vez... co-autoria em narrativas coletivas intersecionadas por tecnologias digitais. In: XII SIMPÓSIO BRASILEIRO DE INFORMÁTICA NA EDUCAÇÃO: EDUCAÇÃO A DISTÂNCIA MEDIADA POR COMPUTADOR, 2001, Vitória -ES, p. 136-144. Anais eletrônicos. Disponível em: http://www. ufrgs.br/lelic/files_gerenciador_de_arquivos/artigo/2001/56/1371064145anais_ congresso_era_uma_vez.pdf. Acesso em: 05 mar. 2017.

BARATO, Jarbas Novelino. Prefácio. In: ABAR, Celina A. A.; BARBOSA, Lisbete Madsen. WebQuest - um desafio para o professor! Uma solução inteligente para o uso da internet. São Paulo: Avercamp Editora, 2008, p. 5-8.

BARCA, Isabel. Narrativas e consciência histórica dos jovens. Enseñanza de las Ciências Sociales - Revista de Investigação Didática, p. 10-28, 2010. Disponível em: http: https://core.ac.uk/download/pdf/39105418.pdf. Acesso em: 10 jul. 2016.

BARROS, José d'Assunção. Tempo e narrativa em Paul Ricoeur: considerações sobre o 
círculo hermenêutico. Fênix - Revista de História e Estudos Culturais. UberlândiaMG, v. 09, n. 1, p. 1-27, 2012.

CYSNEIROS, Paulo Gileno. Novas tecnologias na sala de aula: melhoria do ensino ou inovação conservadora?. In: ENCONTRO NACIONAL DE DIDÁTICA E PRÁTICA DE ENSINO, 1998, São Paulo. Anais Endipe,1998, São Paulo. p. 199-216. Disponível em: http://www.pucrs.br/ciencias/viali/doutorado/ptic/aulas/aula_1/articles-106213_archivo.pdf. Acesso em: 05 fev. 2017.

DODGE, Bernie. Taskonomia: uma taxonomia de tarefas. 1999. Disponível em: http:// www.nce.ufrj.br/ginape/iga502/Material_aulas/Taskonomia\%20\%20Taxonomia\%20das\%20Tarefas.doc. Acesso em: 05 set. 2016.

DODGE, Bernie. WebQuest - Entrevista com Bernie Dodge. 1997. Disponível em: https://www.youtube.com/watch?v=IPgdXij68sc. Acesso em: 02 ago. 2018.

DODGE, Bernie. WebQuest: uma técnica para aprendizagem na rede internet. 1996. Disponível em: http://www.WebQuest.futuro.usp.br/artigos/textos_bernie.html. Acesso em: 02 jul. 2017.

GIOVANNI, Adaiane. As tecnologias no ambiente escolar: estudo sobre o desempenho dos alunos do $3^{\circ}$ ano do Ensino Médio com a metodologia WebQuest. Dissertação (Mestrado Interdisciplinar Sociedade e Desenvolvimento). Campo Mourão: Universidade Estadual do Paraná, UNESPAR, Paraná, 2016. Disponível em: http:// ppgsed.unespar.edu.br/menu-principal/dissertacoes-1/discentes-2014-1. Acesso em: 05 jun. 2016.

GUTIERREZ, Horácio. Donos de Terras e Escravizados no Paraná: Padrões e Hierarquias nas primeiras décadas do século XIX. História. São Paulo. V. 25. N.1, p. 100122, 2006.

HAHN, Fábio André; NASCIMENTO, Éder Dias do. A presença dos escravos nas fazendas do Paraná - século XIX (caso 5). Janela para a história, 2018. Disponível em: http://janelaparaahistoria.unespar.edu.br/caso5.html. Acesso em: 02 jan. 2020.

HARKOT-DE-LA-TAILLE, Elizabeth; SANTOS, Adriano Rodrigues. Sobre escravos e escravizados: percursos discursivos da conquista da liberdade. In: III SIMPÓSIO NACIONAL DISCURSO, IDENTIDADE E SOCIEDADE I SIMPÓSIO INTERNACIONAL DISCURSO, IDENTIDADE E SOCIEDADE, 2012, Campinas-SP. Anais eletrônicos. Disponível em: https://www.iel.unicamp.br/sidis/anais/pdf/HARKOT_DE_LA_TAILLE_ELIZABETH.pdf. Acesso em: 04 abr. 2020.

JÚLIA, Dominique. A cultura escolar como objeto histórico. Tradução de Gizele de Souza. Revista Brasileira de História da Educação. Campinas: Editora Autores Associados, no 1, p. 9-43, 2001. JÚLIO, Josimeire M.; SILVA, Arnaldo de M. Vaz. Atividades de investigação escolar: análise psicanalítica do engajamento em pequenos grupos. Cadernos de Pesquisa, v. 40, n. 141, p. 921-941, 2010.

JUNIOR, Bottentuit João B.; COUTINHO, Clara P. Análise de WebQuests em língua 
portuguesa disponíveis on-line: aspectos relativos à qualidade dos componentes e da usabilidade. Revista Brasileira de Estudos Pedagógicos, v. 90, p. 102-121, 2009.

MORAN, José. Metodologias ativas para uma aprendizagem mais profunda. Revista Educatrix. São Paulo. n. 12, 2017.

MOURA, Antonio Guanacuy Almeida. WebQuest's: possibilidades no ensino e aprendizagem de história. Dissertação de Mestrado (Programa de Pós-Graduação em Ensino de História). Universidade Federal do Tocantins, UFT, 2018. Disponível no acervo do site: https://educapes.capes.gov.br/. Acesso em: 10 jan. 2019.

REUTER, Yves. A análise da narrativa: o texto, a ficção e a narração. Tradução de Mário Pontes. Rio de Janeiro: DIFEL, 2002.

RICOEUR, Paul. Tempo e narrativa. Tomo I. Tradução de Constança Marcondes Cesar. Campinas, SP: Papirus, 1994.

RÜSEN, Jorn. El desarrollo de la competência narrativa en el aprendiaje histórico. Una hipótesis ontogenética relativa a la conciencia moral. Revista Propuesta Educativa, Buenos Aires. n. 7, p. 27-36. 1992. Tradução de Ana Claudia Urban e Flávia Vanessa Starcke.

RÜSEN, Jörn. História viva: teoria da história III: formas e funções do conhecimento histórico. Brasília, Distrito Federal: Editora da UnB, 2007.

RÜSEN, Jörn. O desenvolvimento da competência narrativa na aprendizagem histórica: uma hipótese ontogenética relativa à consciência moral. In: SCHMIDT, Maria Auxiliadora Moreira dos Santos; BARCA, Isabel; MARTINS, Estevão de Rezendes (Orgs.). Jörn Rüsen e o ensino de história. Curitiba, PR: Editora da UFPR, 2010, p. 51-78.

RÜSEN, Jörn. O desenvolvimento da competência narrativa na aprendizagem histórica: uma hipótese ontogenética relativa à consciência moral. 1992. Disponível em: https://edisciplinas.usp.br/pluginfile.php/1172513/mod_resource/content/1/Jorn\%20 Rusen\%20e\%20o\%20Ensino\%20de\%20Hist\%C3\%B3ria.pdf.. Acesso em: jan. 2018.

RÜSEN, Jörn. Razão histórica: teoria da história: fundamentos da ciência histórica. Brasília, Distrito Federal: UnB, 2010a.

SANT, Edda et al. ¿Cómo podemos analizar la competencia narrativa del alumnado en el aprendizaje de la Historia? Clío \& Asociados. p. 166-182, 2014. Disponível em: https://www.researchgate.net/publication/281413164_Narrativas_y_discursos_como_ podemos_analizar_la_competencia_narrativa_del_alumnado_en_el_aprendizaje_ de_la_Historia. Acesso em: 10 out. 2015.

SCARRANARO, Márcia Maria. Aula de História: uma perspectiva colaborativa na produção de conhecimento no ensino médio. Dissertação (Mestrado em linguística aplicada e estudos da linguagem). Pontifícia Universidade Católica de São Paulo. São Paulo, 2010. Disponível em: http://www.dominiopublico.gov.br/pesquisa/DetalheObraForm.do?select_action=\&co_obra=190108. Acesso: 15 fev. 2017.

SOARES, Maria Teresa Carneiro; PINTO, Neusa Bertoni. Metodologia da resolução de problemas. In: 24a REUNIÃO ANPED, 2001, Caxambu/Minas Gerais. Anais do 
Anped, 2001, Caxambu/ Minas Genais. p. 1-9. Disponível em: http://www.anped. org.br/reunioes/24/tp1.htm\#gt19. Acesso em: 4 set. 2012.

SPAGNOLO, Carla; MANTOVANI, Ana Margô. Aprendizagem colaborativa na educação escolar: novas perspectivas para o processo de ensinar e aprender. Santos: Revista Digital da CVA - Ricesu v. 8, n. 30, 2013.

TORRES, Patrícia Lupion; IRALA, Esrom Adriano Freitas. Aprendizagem colaborativa teoria e prática. Curitiba: Coleção Agrinho, 2014. Disponível em: https://www.agrinho.com.br/site/wp-content/uploads/2014/09/2_03_Aprendizagem-colaborativa. pdf. Acesso em: 10 fev. 2018

\section{NOTAS}

${ }^{1}$ A criação da metodologia WebQuest também contou com a colaboração de um ex-discente de graduação de Dodge - Tom March.

${ }^{2}$ Um repositório de WebQuests de várias disciplinas escolares, inclusive de História, é o site Inovar, disponível no endereço virtual: http://www.inovar.pt/cre/phpwebquest/procesa_index_todas.php.

${ }^{3}$ Destacamos as dissertações de mestrado de Antônio Guanacuy Almeida Moura (2018) e de Adaiane Giovanni (2016). No tocante ao desenvolvimento de projetos de pesquisa e sites da internet voltados à WebQuest, destacamos os trabalhos mais recentes do professor Fábio André Hahn, da Universidade Estadual do Paraná/UNESPAR, e das professoras Keila Grinberg e Anita Almeida, da Universidade Federal do Estado do Rio de janeiro/UNIRIO, com o site Detetives do Passado.

${ }^{4} \mathrm{~A}$ consciência histórica é a forma como os sujeitos lidam com a temporalidade de suas vidas ao manusearem as dimensões do passado, presente e futuro (RÜSEN, 2010a, p. 57). Em termos práticos, é a forma como construímos nossa identidade, a ideia de quem somos e de quem são os outros e como agir perante as situações da vida cotidiana.

${ }^{5}$ No campo das pesquisas stricto senso ensino de história, com enfoque prioritário no trabalho colaborativo, há o caso da dissertação intitulada "Aula de História: uma perspectiva colaborativa na produção de conhecimento no Ensino Médio", da pesquisadora Márcia Maria Scarranaro (2010). Contudo, apesar do destaque dado ao trabalho Scarranaro, não se trata de uma iniciativa cuja preocupação seja o uso escolar da internet.

${ }^{6}$ Segundo Dodge, as WebQuests são sobretudo atividades de grupos, embora possam ser imaginadas investigações individuais aplicáveis à educação a distância e ao ambiente de bibliotecas (1996, p. 2).

${ }^{7}$ Em razão dessa escolha, nos distanciamos dos estudos que utilizam a narrativa para investigar a consciência histórica, como os realizados, por exemplo, por vários pesquisadores ligados ao Laboratório de Pesquisa em Educação Histórica - LAPEDUH da Universidade Federal do Paraná-UFPR.

${ }^{8}$ Entendemos a competência narrativa como um dos objetivos do ensino de História. E do 
mesmo modo, uma forma de entender o fenômeno da narrativa em sua relação com a vida prática. Notadamente, ela também nos serve como parâmetro avaliativo das produções estudantis, pensadas aqui da perspectiva de compreensão do processo de resolução da atividade proposta e não de mapeamento de erros e acertos dos estudantes.

${ }^{9} \mathrm{O}$ questionamento A narrativa segue uma trajetória complexa?, integrante do instrumento originalmente pensado por Sant et al (2014), não será apreciado neste estudo porque, a nosso ver, a escala de avaliação das tramas sugerida pelos idealizadores do instrumento permite estabelecer um perfil das produções, mas pouco contribui para pensar questões ligadas à WebQuest aplicada, uma das pretensões de nossa investigação. Por esse motivo, das 15 questões originalmente propostas, somente 14 foram utilizadas.

${ }^{10}$ As turmas participantes da pesquisa foram assim denominadas: o oitavo da manhã, com 25 estudantes, de "8-X"; o da tarde, com 21 estudantes, de "8-H"; o segundo ano do Ensino Médio da manhã, com 27 estudantes, de "2-M" e, por fim, o segundo da noite, com 12 estudantes, " $2-\mathrm{K}$ ". Para fins de análise dos resultados, quando houve a necessidade de juntar as amostras, formamos os seguintes grupos: $8-\mathrm{X}+8-\mathrm{H}$ e $2-\mathrm{M}+2-\mathrm{K}$.

${ }^{11}$ Segundo Elizabeth Harkot-de-La-Taille e Adriano Rodrigues dos Santos, o termo "escravo" remete a uma visão histórica pautada no discurso de submissão do negro a condição social imposta pela sociedade escravista que existiu no Brasil. Por outro lado, o termo "escravizado", mais correto, carrega em si a carga semântica da luta do negro contra escravidão (2012). No presente artigo utilizaremos a palavra "escravo" somente quando nos referirmos ao título e nomes de algumas seções da WebQuest, já publicada. Contudo, no restante do trabalho empregaremos a palavra "escravizado", conforme o entendimento de Harkot-de-La-Taille e Santos.

${ }^{12}$ Nas WebQuests do tipo compilação "os alunos são familiarizados com conteúdos que exigem selecionar, explicar, ordenar, reconhecer e apresentar um produto final com a organização da informação. O produto final pode ser, por exemplo, a implementação de uma base de dados" (ABAR e BARBOSA, 2008, p. 40-41).

${ }^{13} \mathrm{O}$ primeiro nível abriga os critérios autenticidade e organização, e o segundo, pesquisa.

${ }^{14}$ A abordagem narratológica pode apresentar duas características: as narrativas podem ser entendidas "como objetos linguísticos, fechados em si, independentemente de sua produção e recepção" ou, numa perspectiva mais abrangente, podem se basear no entendimento de que existem "formas de base e princípios de composição comuns" a toda e qualquer narrativa (REUTER, 2002, p. 9-10).

${ }^{15}$ Ao utilizar o conceito de "narrativa histórica", a reflexão desenvolvida neste artigo alinha-se com a percepção de Isabel Barca "de uma narrativa construída com base na evidência disponível, que considera vários pontos de vista e, por isso, se afasta de uma grande narrativa, entendida como retrato consensual do passado" (BARCA, 2010, p. 23). No entendimento da autora, narrativa não é a simples descrição objetiva, pragmática e sistêmica do passado, mas a aceitação ou compreensão das diferentes versões do passado e de seu potencial de mutabilidade com os avanços da própria ciência histórica. Enfim, não seria somente repetir determinado dado histórico sem uma devida reflexão sobre ele. 
${ }^{16}$ Não se trata das narrativas em sua integralidade, mas dos fragmentos que remetem a determinadas elaborações dotadas de inventividade e criatividade.

${ }^{17}$ Segundo José de Assunção Barros, em alusão às ideias de Paul Ricoeur, a "possibilidade de figurar ações humanas em linguagem já está incluída na própria língua, e caberá ao construtor de narrativas acrescentar a esses materiais e situações que se disponibilizam na língua uma série de especificidades discursivas que darão a cada narrativa, em sentido estrito, uma configuração própria e singular. 'Trair', narrativa presente na própria língua, transforma-se na 'traição de Judas em relação a Jesus', especifica-se” (2012b, p. 7).

${ }^{18}$ Ao nos referirmos à reprodução de uma mesma rotina na execução da tarefa proposta, destacamos a presença, a contragosto de alguns avanços, de determinado modelo de interação com conteúdo ensinado que ainda é muito vivo no ensino de História, que, em linhas gerais, é marcado por uma forma de reprodução em que os estudantes entregam a atividade proposta, mas com um envolvimento de natureza apenas formal, sem empreender um enlace intelectual, emocional e criativo mais direto com ela.

${ }^{19}$ Na visão de Maria Teresa Carneiro Soares e Neuza Bertoni Pinto, uma "das formas mais acessíveis de proporcionar aos alunos que aprendam a aprender é a utilização da resolução de problemas como metodologia de ensino. A solução de problemas baseia-se na apresentação de situações abertas e sugestivas que exijam dos alunos uma atitude ativa ou um esforço para buscar suas próprias respostas, seu próprio conhecimento. O ensino baseado na solução de problemas pressupõe promover nos alunos o domínio de procedimentos, assim como a utilização dos conhecimentos disponíveis, para dar resposta a situações variáveis e diferentes" (2001, s. p).

${ }^{20}$ Nas WebQuest's do tipo mistério há sempre um desafio que "requer síntese de variadas informações e não pode ser resolvido de modo simples. As experiências reais ou imaginárias de historiadores, arqueólogos, detetives e outros podem servir de incentivo para o desafio a ser enfrentado" (ABAR e BARBOSA, 2008, p. 40-42).

${ }^{21}$ Nesse tipo de WebQuest "os alunos são colocados no papel de engenheiros, inventores, artistas, incentivando a criatividade e a expressão livre na elaboração de um produto" (ABAR e BARBOSA, 2008, p. 42).

${ }^{22}$ Mesmo que se reconheçam os avanços metodológicos e a renovação das práticas de ensino da História escolar, o livro didático continua a ser um dos principais recursos empregados por considerável parte dos professores desta disciplina. A expressão "livresca e muito textual" diz respeito à observação desta especificidade, responsável por criar a falsa impressão de que a História tem como principal e único objetivo o trabalho de leitura e intepretação de textos.

Artigo recebido em 16 de fevereiro de 2020. Aprovado em 2 de maio de 2020. 